\title{
Preliminary electrochemical characterization of anode supported solid oxide cell (AS-SOC) produced in the Institute of Power Engineering operated in electrolysis mode (SOEC)
}

\author{
JAKUB KUPECKI* \\ KONRAD MOTYLIŃSKI \\ MAREK SKRZYPKIEWICZ \\ MICHAE WIERZBICKI \\ YEVGENIY NAUMOVICH
}

Department of High Temperature Electrochemical Processes, Institute of Power Engineering, Augustowka 36, 02-981 Warsaw, Poland

\begin{abstract}
The article discusses the operation of solid oxide electrochemical cells (SOC) developed in the Institute of Power Engineering as prospective key components of power-to-gas systems. The fundamentals of the solid oxide cells operated as fuel cells (SOFC - solid oxide fuel cells) and electrolysers (SOEC - solid oxide fuel cells) are given. The experimental technique used for electrochemical characterization of cells is presented. The results obtained for planar cell with anodic support are given and discussed. Based on the results, the applicability of the cells in power-to-gas systems (P2G) is evaluated.
\end{abstract}

Keywords: SOFC; SOEC; Electrolysis; Power-to-gas

\section{Introduction}

High temperature fuel cells become increasingly attractive technologies for highly efficient power generation. Both the molten carbonate (MCFC) and solid oxide fuel cell (SOFC) are applied in various demonstration systems.

${ }^{*}$ Corresponding Author. Email jakub.kupecki@ien.com.pl 
While several commercial plants based on MCFC can be found worldwide, the market penetration of SOFC is not as reconisable. The features of both types of cells enable their use in novel applications. The earlier is considered as a strong candidate for $\mathrm{CO}_{2}$ separation, which can compete with such technologies as MEA-based CCS (carbon capture and storage) units [1]. The latter can operate in regenerative mode as the solid oxide electrolyser (SOEC). Solid oxide electrolysis is believed to be the most attractive solution for power-to-gas (P2G) and power-to-liquid (P2L) systems [2]. Moreover, electrolysis can find good application in biomass-to-liquid (BTL) systems for enhancing the conversion of the feeding gas by combining the gasification and solid oxide electrolyser [3].

The solid oxide cell can operate in interchangeable mode on condition that the material compatibility is assured. The most typical mechanism of the degradation of SOC during the change between the SOFC and SOEC mode is caused by the electrode delamination [4]. Certain ceramic oxides, including the lanthanum strontium cobaltite ferrite (LSCF), exhibit good stability in the electrolyser mode and the rapid degradation is therefore prevented. Once the stability issues are resolved and the ability for longterm operation is demonstrated, the SOEC unit can be the key component of the energy storage systems, which realize the power-to-gas concept. The high temperature electrochemical processes occurring in solid oxide cells (SOC) can proceed both ways depending on the operational mode: current generation from fuel gas (e.g., hydrogen, $\mathrm{CO}$ ) or steam electrolysis powered from outside (e.g., from grid).

\section{Solid oxide electrolysis - theoretical background}

The chemical energy of fuel can be converted into electricity or the electricity can be used for steam electrolysis. The former concept has been known for years as solid oxide fuel cell, while the latter known as solid oxide electrolysis cell has gained a lot of attention in the last decade. Ability of the SOC to operate interchangeably between the modes allows in one system to either deliver electricity or produce the synthetic fuel which can be a new vector in power generator sector and serve as a storage medium. The integration of renewable energy sources such as wind and photovoltaics causes several issues to the electrical grid. Mostly, due to the intermittent character of these sources, the grid experiences imbalances which destabilize the energy system. Use of SOEC enable utilization of the excess electricity 
and production of the gas which can be stored for direct use during the peak hours or can be further processed to produce synthetic natural gas (SNG). The generated fuel can be injected into gas grids or used for various applications, including transportation. Reversion of the fuel cell operation mode can be done in a dynamic mode during operation within minutes. Such system can be easily modulated and is able to frequently interchange between power-to-gas and gas-to-power modes. SOC allows therefore the coupling of two sectors: electrical and the gas. This increases the flexibility of the combined electrical-gas grids, provides extensive storage capacities and allows way higher modulation than two separate standalone systems.

The advantages of solid oxide electrolysis over the conventional electrolysers should be noted:

- SOEC offers an outstanding efficiency, exceeding 70-80\% [5],

- noble metals are not required due to sufficient catalytic activity of the ceramic materials of electrodes at elevated temperatures,

- SOEC mode can be switched to SOFC and the interchange supports the unique self-healing of the cells [6],

- modular design makes it easy to scale-up the system based on SOC stack,

- absence of liquid electrolyte which has to be replaced on regular basis due to evaporation, hydration or contamination.

The solid oxide electrolysis overcomes therefore the drawbacks of low temperature electrolysis which include: (i) higher terminal voltage by 150 $300 \mathrm{mV}$, (ii) accumulation of impurities in the liquid electrolyte which has to be replaced, (iii) highly expensive catalysts based on noble metals, (iv) inability to operate reversibly.

The interchangeable operation of solid oxide cells relies on reversing the directions of occurring electrochemical processes. In such a case, the roles of electrodes change and the SOFC anode (electrode on which oxidation of species occurs) becomes the cathode (electrode on which reduction of species occurs) in SOEC mode. The working conditions in the anodic and cathodic compartments change as well. The basic comparison of the parameters in fuel cell and electrolyser modes is shown in Fig. 1.

Modifications, which are needed for obtaining stable operation as the reversible solid oxide cell (ReSOC) in a stack, include adaptation of the cell electrodes, interconnectors and the sealings due to the fact that the working 

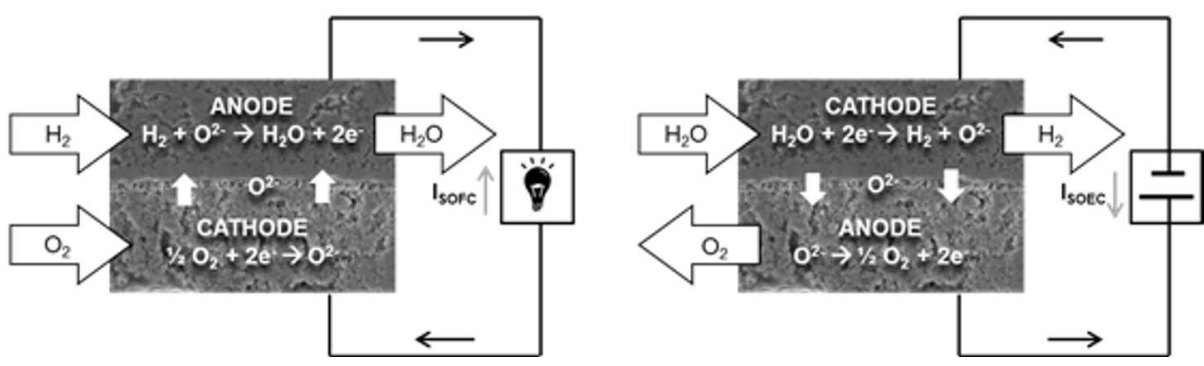

Figure 1: Comparison of the fuel cell (SOFC) and electrolysis (SOEC) operation.

conditions inside the anodic and cathodic compartments of the solid oxide cells operated as electrolysers and as fuel cells alter. The interchangeable SOEC/SOFC operation exposes the cell to both sets of conditions.

\section{Experimental evaluation of SOEC}

The purpose of the recent study presented in the article was to assess the performance of existing cell in order to verify its operation as the electrolyser and to verify that the current composition of the cells qualifies them for the reversible operation. The study was aimed at identification of improvements which are needed for optimization of the cell to operate as ReSOC with a special focus on the SOEC mode.

The cells with external dimensions of $50 \mathrm{~mm} \times 50 \mathrm{~mm}$ and the thickness about $1 \mathrm{~mm}$ were manufactured in the Ceramic Department (CEREL) of the Institute of Power Engineering (IEN) and experimentally characterized in the laboratories of the Department of High Temperature Electrochemical Processes (HiTEP) of IEN. Cross-section of the cell is shown in Fig. 2 and the main parameters of the cell are summarized in Tab. 1.

The LSCF electrodes, which were fabricated as SOFC cathodes, already confirmed to be sufficient as anodes (oxygen electrode) in SOEC $[7,8]$, however the adaptation of porosity and barrier interlayers is needed to assure the long-term stability, reversibility of current and the reduction of the fuel cell degradation. Experimental characterization of the SOFC and SOEC was done in a ceramic housing which accommodates a single $50 \mathrm{~mm} \times 50$ $\mathrm{mm}$ cell. The active area of the currently analysed cell was $16 \mathrm{~cm}^{2}$. For all electrochemical measurements, electrochemical workstation Zahner Im6ex coupled with PP240 4-quadrant power potentiostat were used. The exper- 

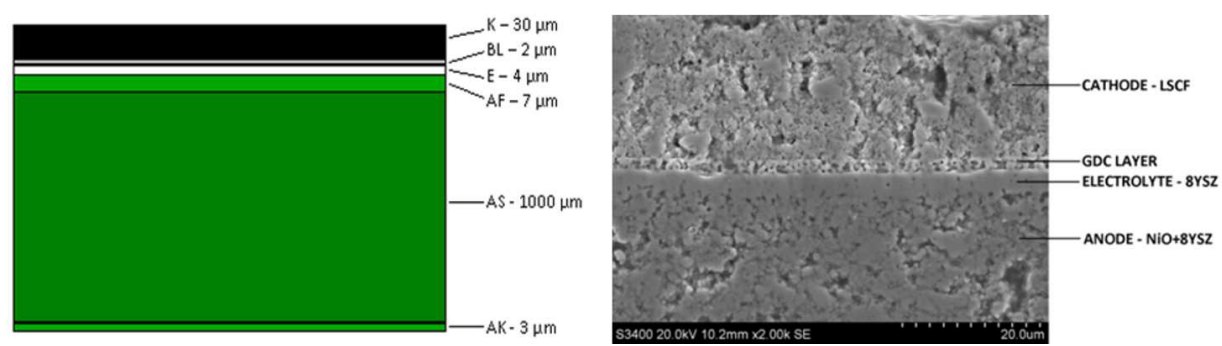

Figure 2: The cross-section of the cell with dimensions of interlayers (left) and their microstructure (right).

Table 1: Basic specification of the cell which was characterized in the SOFC and SOEC modes.

\begin{tabular}{|l|c|c|c|}
\hline Layer & Material & Thickness & Porosity \\
\hline \hline Cathode layer (K) & $\mathrm{La}_{0.6} \mathrm{Sr}_{0.4} \mathrm{Fe}_{0,8} \mathrm{Co}_{0.2} \mathrm{O}_{3--\delta}$ & $30 \mu \mathrm{m}$ & 25 vol.\%. \\
\hline Barrier layer (BL) & $\mathrm{Gd}_{0,1} \mathrm{Ce}_{0,9} \mathrm{O}_{2}$ & $1.5 \mu \mathrm{m}$ & - \\
\hline Electrolyte (E) & $8 \mathrm{YSZ}$ & $4 \mu \mathrm{m}$ & - \\
\hline Anode functional layer (AF) & $\mathrm{NiO} / 8 \mathrm{YSZ} 50 / 50$ wt. $\%$ & $7 \mu \mathrm{m}$ & - \\
\hline Anode support (AS) & $\mathrm{NiO} / 8 \mathrm{YSZ} 66 / 34$ wt. $\%$, & $1.0 \mathrm{~mm}$ & 25 vol. $\%$ \\
\hline Anode contact layer (AK) & $\mathrm{NiO}$ & $3 \mu \mathrm{m}$ & - \\
\hline
\end{tabular}

imental setup used for the preliminary electrochemical characterization of the cell is shown in Fig. 3.

The electrochemical performance of solid oxide cells is dependent on several operation parameters, for the fuel cell mode including: (i) temperature, (ii) fuel flow, (iii) oxidant flow, (iv) composition of the fuel. Under these conditions, the current is varied in order to observe the voltage of the cell.

The experimental setup relies on Bronkhorst mass-flow controllers, $\mathrm{K} / \mathrm{N}$ type thermocouples, Kikusui power electronics. This assures that the measurements are done with high accuracy with error lower than $1 \%$. In-house software was used for acquisition and processing of the process data.

The key parameters which can be determined, include the fuel utilization, the oxidant utilization, efficiency and power obtained from a single cell. In the electrolysis mode, the methodology is analogical with the differences related to the composition of the incoming gases. Once the SOEC is 

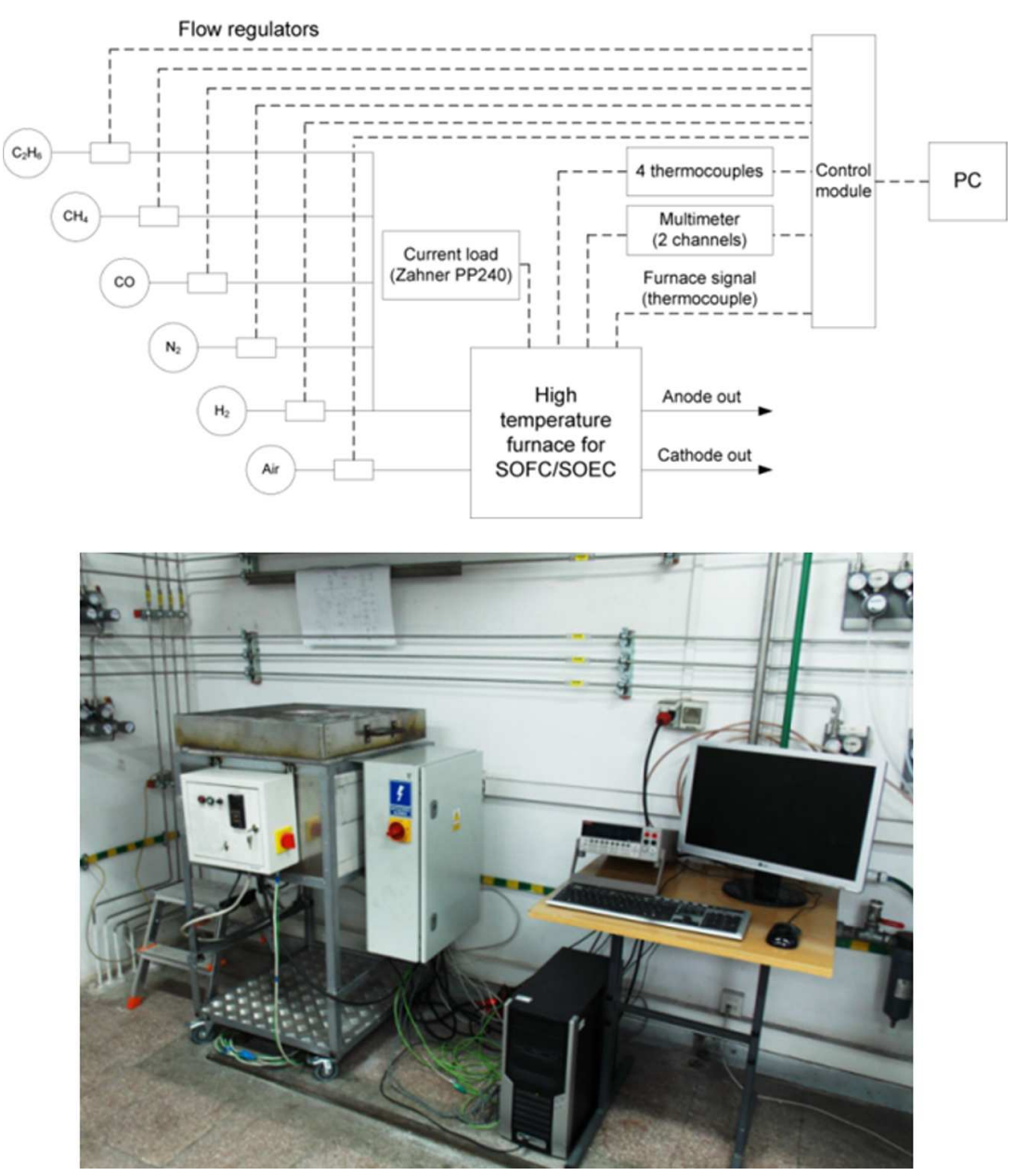

Figure 3: Experimental setup used for characterization of the $50 \mathrm{~mm} \times 50 \mathrm{~mm}$ SOC operated as SOEC: test stand scheme (upper) and the actual photo (lower).

considered, the cathode is supplied with steam, while the exiting gases are the oxygen and hydrogen for the anode and cathode, respectively. Steam delivery in the experimental setup is organized using a precise steam generator (not shown in Fig. 3) which allows humidification of the incoming fuel to the set level. In the electrolysis mode the steam from the generator is premixed with the fuel.

The measurements were performed at the temperature of $850^{\circ} \mathrm{C}$. Over the entire duration of the experiments, the variation of temperature of the 
cell in range $849-855^{\circ} \mathrm{C}$ was observed. The fluctuations were caused by transition from the exothermic conditions to the endothermic conditions and backwards, also passing the cell thermoneutral point $(\sim 1290 \mathrm{mV})$. The temperature variations equal to the maximum of $0.58 \%$ from the set point $\left(5^{\circ} \mathrm{C} / 850^{\circ} \mathrm{C}\right)$, therefore relatively high stability of the temperature was achieved during the measurements. Constant volumetric flow of reagents was supplied to the anodic and cathodic compartments (defined for fuel cell mode) equal to $200 \mathrm{ml}_{N} / \mathrm{min}$ and $400 \mathrm{ml}_{N} / \mathrm{min}$, respectively. The mixture of $\mathrm{H}_{2}$ and $\mathrm{H}_{2} \mathrm{O} 50 \% / 50 \%$ was supplied continuously to the anode to allow the ease of transition between SOFC/SOEC operation modes and air was constantly supplied to the oxygen electrode.

\section{Results}

In order to observe the performance of the cell operated in reversible SOFC/SOEC modes, the experimental methodology included transition from fuel cell to electrolysis mode and backwards. With such an approach it was possible to measure the current while gradually increasing the voltage in potentiostat mode. In the performed experiment, the maximum current achieved in the fuel cell mode was $25 \mathrm{~A}$ and in electrolysis mode $-40 \mathrm{~A}$. The reported values represent the maximum current which was drawn and applied in the fuel cell and electrolysis modes, respectively. The values indicate the ability of the cell to operate at high current densities, but such conditions lead to rapid degradation of the electrochemical performance. The values should be considered as a possible maximum values observed for a short duration. Long term operation and characterization of SOC is done at moderate current densities which will be described in the next section.

It should be noted that neither the solid oxide cell, nor the experimental methodology were optimized for either the fuel cell or the electrolyser mode of operation. Additionally, the existing ceramic housing which was optimized only for investigation of the fuel cell mode was used. This explained the moderate performance of the cell.

Based on the experimental data, the current density-voltage curve was generated. Fuel cell mode corresponds to the positive value of the current density, while negative current density range defines the electrolysis mode. The results can be seen in Fig. 4. The reversible voltage of $869 \mathrm{mV}$ was observed at open circuit voltage (OCV). Such low value of OCV is a result of 
(1) an "open" cell setup (no sealing) applied and (2) relatively low stream of fuel supplied to the fuel cell compartment - clearly observable in concentration polarization region (Fig. 4 at current densities $>300 \mathrm{~mW} / \mathrm{cm}^{2}$ ). As can be seen in Fig. 4 the polarization of the cell was reversed twice by adapting the current density in order to start the characterization from OCV ( $869 \mathrm{mV}$ ), achieve $400 \mathrm{mV}$ is SOFC mode, achieve $1500 \mathrm{mV}$ in SOEC and finalize the measurements at OCV. The development of hysteresis can be noted.

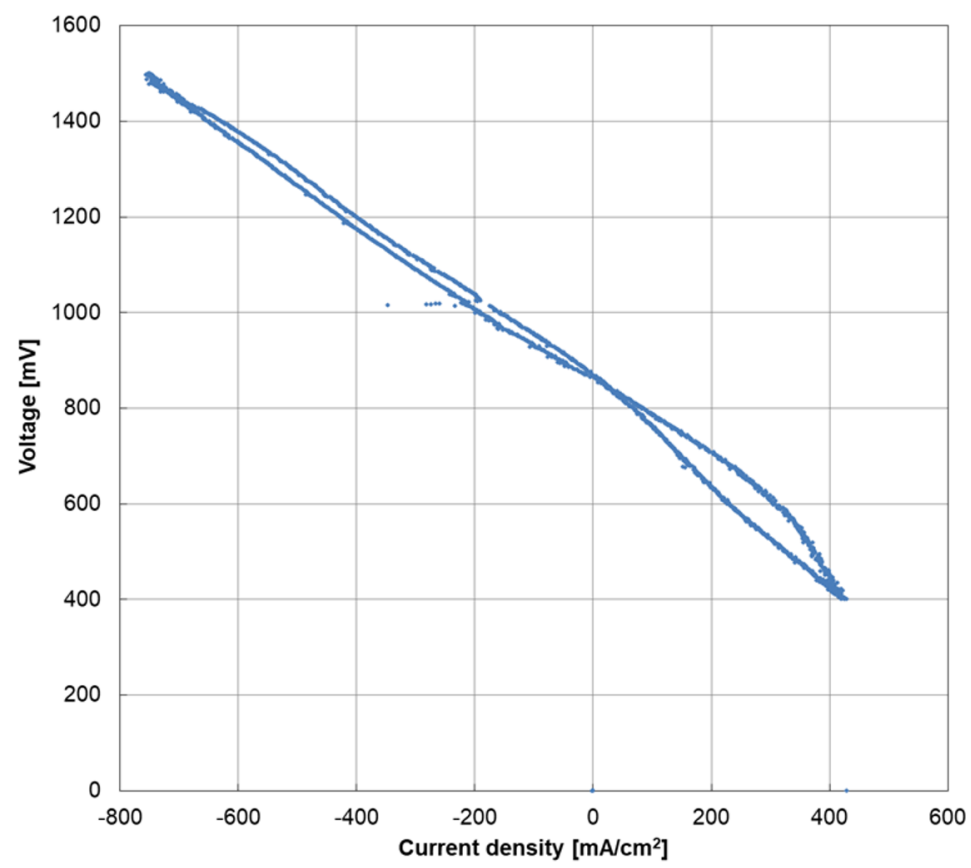

Figure 4: Characterization of the cell during reversion of the polarization between the modes.

The current-voltage characteristics measured in the fuel cell mode was below the typical working conditions of the SOFC cell what was caused by the (1) relatively low stream of fuel supplied to the fuel cell and (2) dilution of fuel with high steam content in the fuel gas both clearly observable in the concentration polarization region. Moreover, the test rig was an 'open - type' cell housing (no sealing), therefore the level of leakages could not be addressed in the current study. 
The SOEC mode curve, measured up to $1500 \mathrm{mV}$ (to avoid the reduction of yttria stabilized zirconia - YSZ) was rather linear, of an area specific resistance (ASR) equal $0.8 \Omega \mathrm{cm}^{2}$ calculated from the current-voltage curve angle at $1050 \mathrm{mV}$.

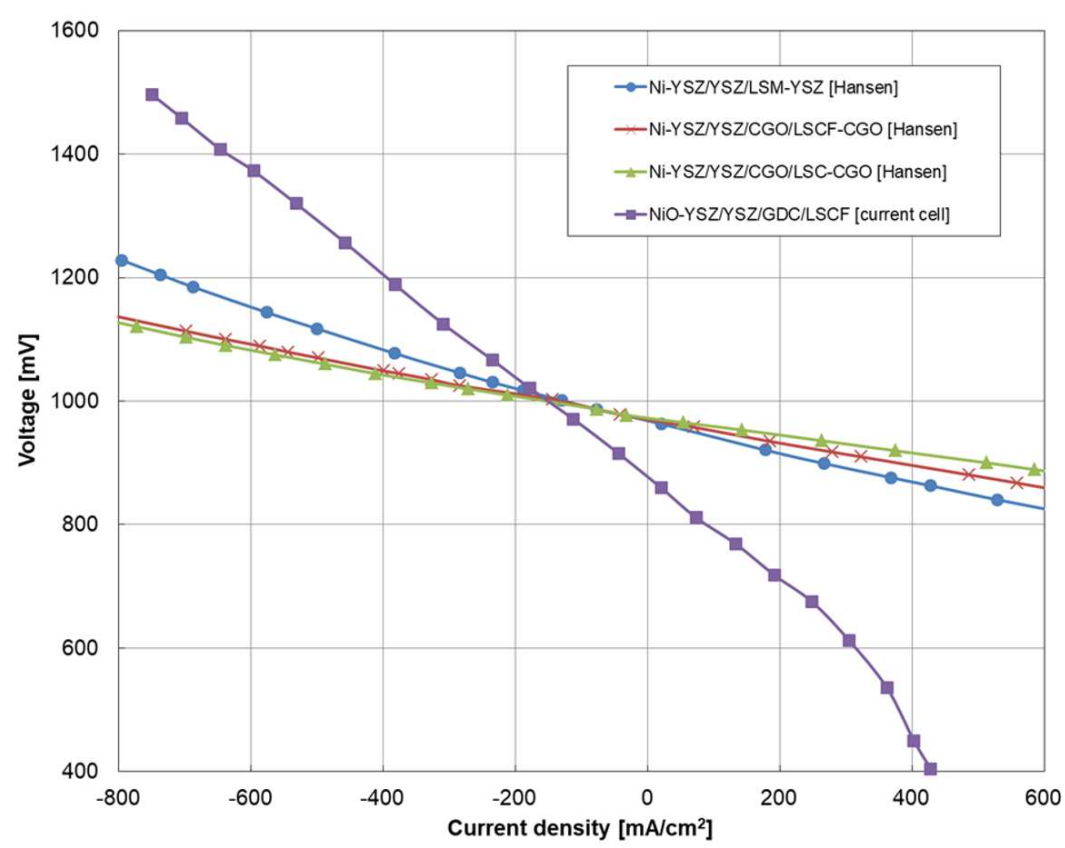

Figure 5: Comparison on the performance of reference cells [9] and the current version of cell at IEN.

Among previous experimental studies related to the operation of the same SOC as a fuel cell and as an electrolyser, the evaluation of NiYSZ/YSZ/LSM-YSZ, Ni-YSZ/YSZ/CGO/LSCF-CGO and Ni-YSZ/YSZ/ /CGO/LSC-CGO cells was done by [9]. For the purpose of comparative analysis, the currently obtained results were plotted against the literature data reported previously. The comparison can be seen in Fig. 5. It should be noted that while the current cell was analyzed at temperature of $850^{\circ} \mathrm{C}$, data reported by Technical University of Denmark [9] were obtained for $800^{\circ} \mathrm{C}$. 


\section{Conclusions}

The preliminary experimental studies confirmed applicability of the solid oxide cells developed and fabricated in the Institute of Power Engineering in short-term operation for operation in electrolysis mode. The moderate performance during the experiment could be explained by the fact that neither the cell itself nor the experimental methodology and setup were optimized for investigation of the reversible operation. The interpretation of the experimental data provide a starting point to elaborate the required modifications of the cell in order to increase the performance in SOEC mode and to reduce long term degradation which can be due to several factors including the delamination of oxygen electrode.

The results of the current study can be combined with outcomes of conceptual studies related to utilization of electrochemical processes for generation of synthetic fuels in hybrid systems [10] or support the carbon capture technologies when the SOEC handles the carbon dioxide operating in co-electrolysis [11].

Finally, the further work needs to be performed that will address the modifications of the experimental methodology and setup, as well as studies of the steam utilization for different $\mathrm{H}_{2} / \mathrm{H}_{2} \mathrm{O}$ compositions involving the electrochemical impedance spectroscopy (EIS) measurements needed to determine the particular losses within the processes.

Acknowledgment Authors would like to acknowledge the valuable comments on the work from Dr. Mariusz Krauz and Dr. Ryszard Kluczowski from the Ceramic Department (CEREL) of the Institute of Power Engineering to whom they express the gratitude. This work was financially supported by the Ministry of Science and Higher Education of the Republic of Poland through the Statutory Grant CPE/1/STAT/2017 in the Institute of Power Engineering.

Received 4 October 2017

\section{References}

[1] Milewski J., WoŁowicz M., Lewandowski J.: Optimization of the working conditions of a laboratory size (100 cm2) molten carbonate fuel cell. ECS Transactions 51(2013), 1, 37-45. 
[2] Schwarze K., Posdziech O., Kroop S. et al:: Green industrial hydrogen via reversible high-temperature electrolysis. ECS Transactions 78(2017), 1, 2943-2952.

[3] Pozzo M., Lanzini A., SAntarelli M.: Enhanced biomass-to-liquid (BTL) conversion process through high temperature co-electrolysis in a solid oxide electrolysis cell (SOEC). Fuel 145(2015), 39-49.

[4] Virkar A.V.: Mechanism of oxygen electrode delamination in solid oxide electrolyzer cells. Int. J. Hydrogen Energ. 35(2010), 18, 9527-9543.

[5] Sun X., Chen M., Jensen S.H., et al.: Thermodynamic analysis of synthetic hydrocarbon fuel production in pressurized solid oxide electrolysis cells. Int. J. Hydrogen Energ. 37(2012), 22, 17101-17110.

[6] Graves C., EbBesen S.D., Jensen S.H., et al.: Eliminating degradation in solid oxide electrochemical cells by reversible operation. Nat. Mater. 14(2015), 239-244.

[7] Jae S., Gyeong K., Choi M.: Stability of LSCF electrode with GDC interlayer in YSZ-based solid oxide electrolysis cell. Solid State Ionics 262(2014), 303-306.

[8] Kim S.J., Kim K.J., DAYAGHi A.M., et al.: Polarization and stability of La2NiO4 $+\delta$ in comparison with La0.6Sr0.4Co0.2Fe0.8O3- $\delta$ as air electrode of solid oxide electrolysis cell. Int. J. Hydrogen Energ. 41(2016), 33, 14498-14506.

[9] Hansen J.B.: Solid oxide electrolysis - a key enabling technology for sustainable energy scenarios. Faraday Discuss. 182(2015), 9-48.

[10] Milewski J.: Solid oxide electrolysis cell co-methanation supported by molten carbonate fuel cell - a concept. J. Power Technologies 96(2016), 1, 8-14.

[11] Bartela L., Skorek-Osikowska A., Kotowicz J.: Integration of a supercritical coal-fired heat and power plant with carbon capture installation and gas turbine. Rynek Energii 100(2012), 3, 56-62. 